\title{
A success of cesarean scar ectopic pregnancy by conservative treatment
}

\author{
Geetha Krishnamoorthy ${ }^{1}$, Aiyswarya ${ }^{2 *}$ \\ ${ }^{1}$ Associate Professor, ${ }^{2}$ Post Graduate, ${ }^{\mathbf{1 , 2}}$ Dept. of Obstetrics and Gynaecology, ${ }^{\mathbf{1 , 2}}$ Vinayaka Misssion Medical College, Karaikal, Puducherry, \\ India
}

*Corresponding Author: Aiyswarya

Email: doctorsaishu@gmail.com

Received: $18^{\text {th }}$ February, 2019

Accepted: $11^{\text {th }}$ March, 2019

\begin{abstract}
Cesarean scar pregnancy which leads to various complications such as massive uncontrollable bleeding, rupture of uterus resulting in infertility and even hysterectomy is a rare variant of ectopic pregnancy. Cesarean scar pregnancy (CSP) is on a raising trend. The diagnosis and confirmation of CSP is by transvaginal and magnetic resonance imaging (MRI) respectively. Monitoring is by repeated checking of beta hCG values until it falls to non pregnant level and patients are followed-up with USG upto complete resolution of the pregnancy sac is evident. As CSP is very rare there is no exact guidelines for treatment approach. Here we prove that cesarean scar pregnancy can be effectively treated by administration of Methotrexate systemically if the patient comes for regular follow up.
\end{abstract}

Keywords: Conservative, Scar pregnancy, Methotrexate.

\section{Introduction}

Cesarean scar pregnancy CSP is a rarest variant of ectopic pregnancy with severe complications. ${ }^{1}$ The incidence of CSP increases as cesarean section has increased. Myometrium of the previous cesarean section scar is the site of implantation .It leads to serious complications such as massive hemorrhage and disruption of uterus requiring hysterectomy. ${ }^{2}$ Early diagnosis help in avoiding fatal complications affecting future fertility and also the woman's life. There are numerous methods of treatment used considering the general condition of the patient - removal of trophoblastic tissues either by laparotomy or laparoscopy, ${ }^{3,4}$ dilatation and curettage, administration of methotrexate locally or systemically, hypogastric artery ligation bilaterally with trophoblastic evacuation, uterine artery embolization with curettage, MTX. ${ }^{6,7}$ So we should be highly vigilant of this dread full complication. ${ }^{12}$

Our case is successfully treated cesarean scar pregnancy by systemic MTX.

In women with a previous cesarean delivery CSP incidence is about $5.9-6.1 \%$ of ectopic pregnancies, about $1 / 1800$ to $1 / 2200$ pregnancies. ${ }^{13,14}$

\section{Case Report}

A 33 year gravida 2, para 1, live 1 with history of 1 previous cesarean section, now at 6 weeks of gestation came with complaints of mild vaginal bleeding. On examination her general conditions was good, vitals were stable and on bimanual examination an enlarged uterus with no adnexal mass was found. A gestational sac around 6 to 7 weeks gestational age with absent cardiac activity in the lower part of uterus was seen in transvaginal ultrasound. No fluid in cul de sac was found. Extension of the sac was till half the depth of the scar area. 1659IU/L was the beta human chorionic gonadotropin (beta-hCG) on the day of admission which was 1494 IU/L the day before. All these findings were in favour of cesarean scar pregnancy. So MRI was done as emergency and it showed a uterus normal in size with a mass of size $2.7 \times 3.2 \times 2.5 \mathrm{~cm}$, irregular in shape probably the gestational sac in the anterior part of lower uterine segment at the previous cesarean scar, reaching till the serosa without disturbing the myometrium thus the diagnosis is confirmed. The posterior part of the bladder dome was seen adjacent to the mass and the mass was even touching the same. No free fluid in the pelvis seen and there was no pelvic lymphadenopathy.

Table 1

\begin{tabular}{|c|c|c|}
\hline Day & BETA hcg values & Inj. Methotrexate \\
\hline 0 & 1659 & 1st dose \\
\hline 4 & 1502 & 2nd dose \\
\hline 10 & 703 & 3rd dose \\
\hline 15 & 400.5 & 4th dose \\
\hline 21 & 132.6 & 5th dose \\
\hline 27 & 45.3 & 6th dose \\
\hline 32 & 24.7 & \\
\hline 39 & Undetectable & \\
\hline
\end{tabular}

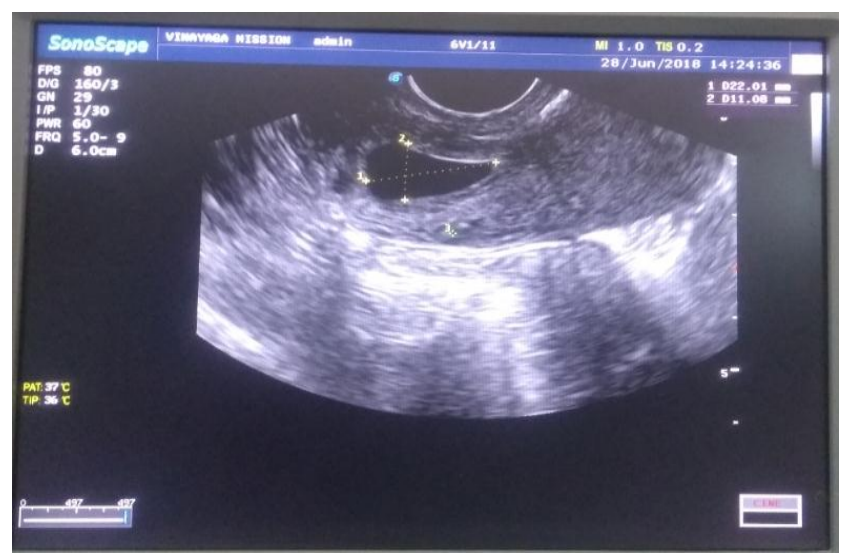

Fig. 1: Gestational sac in the lower anterior wall of the uterus suggesting scar pregnancy. 


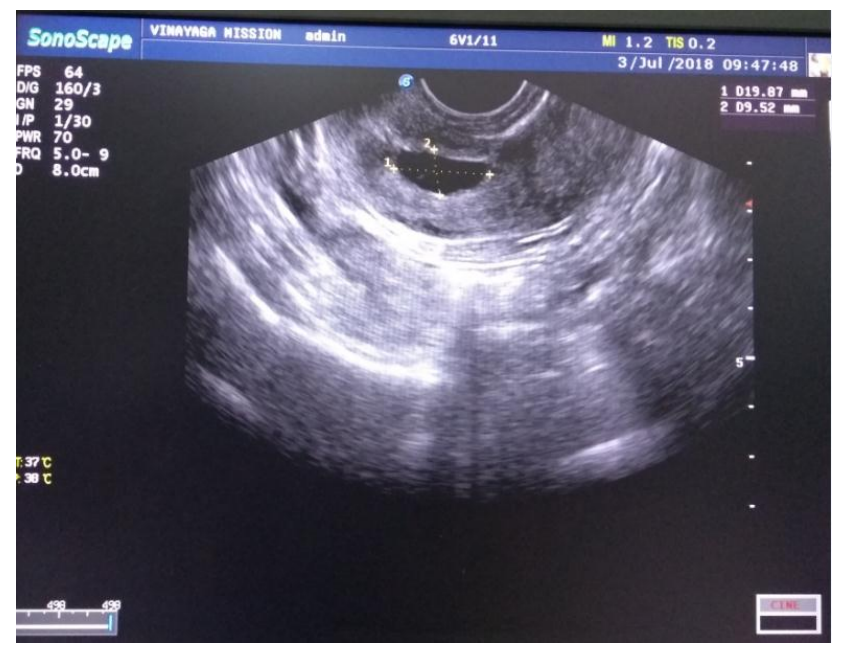

Fig. 2: Persistent scar pregnancy with little decrease in size after 2 doses of MTX on day 10.

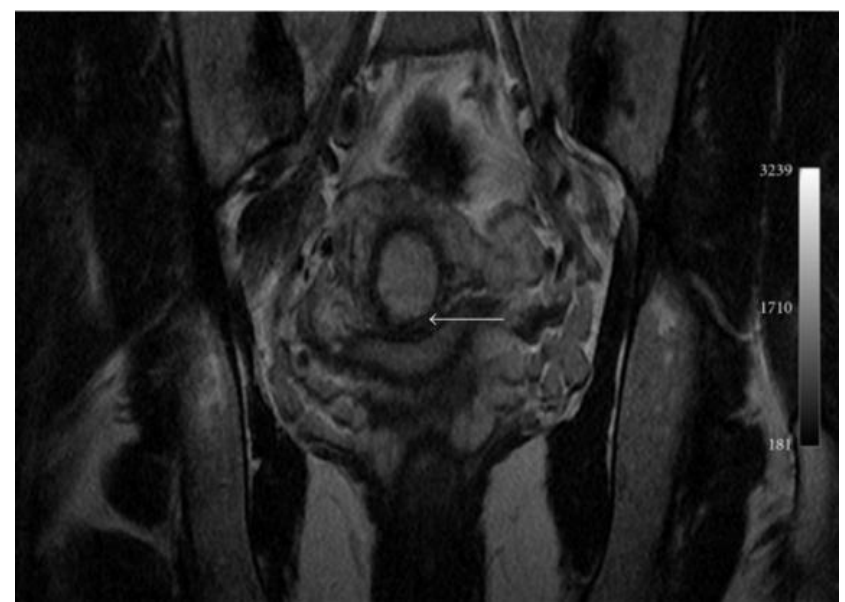

Fig. 3: Magnetic resonance imaging gestational sac surrounded by myometrium (arrow head), absence of myometrium between the gestational sac and the bladder (arrow).

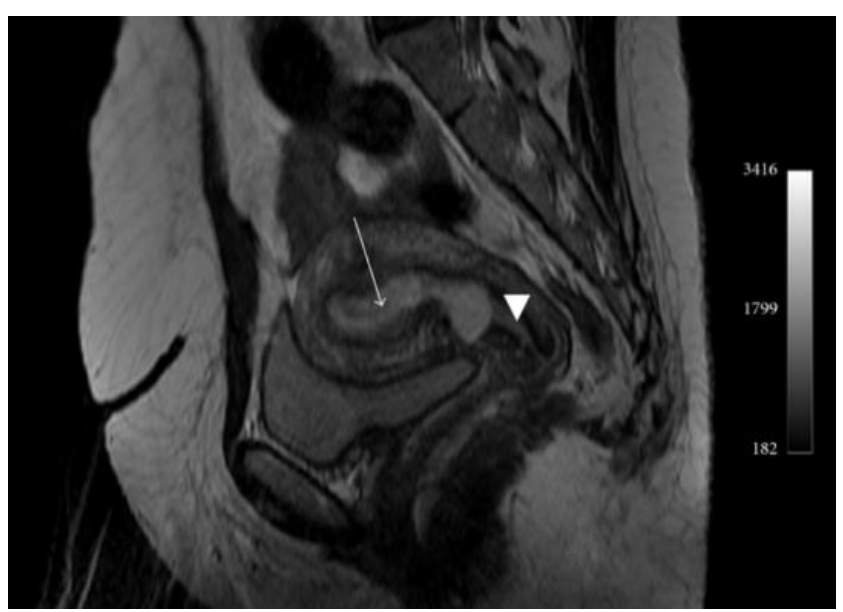

Fig. 4: MRI - arrow showing empty uterus, Arrowhead showing empty cervical canal

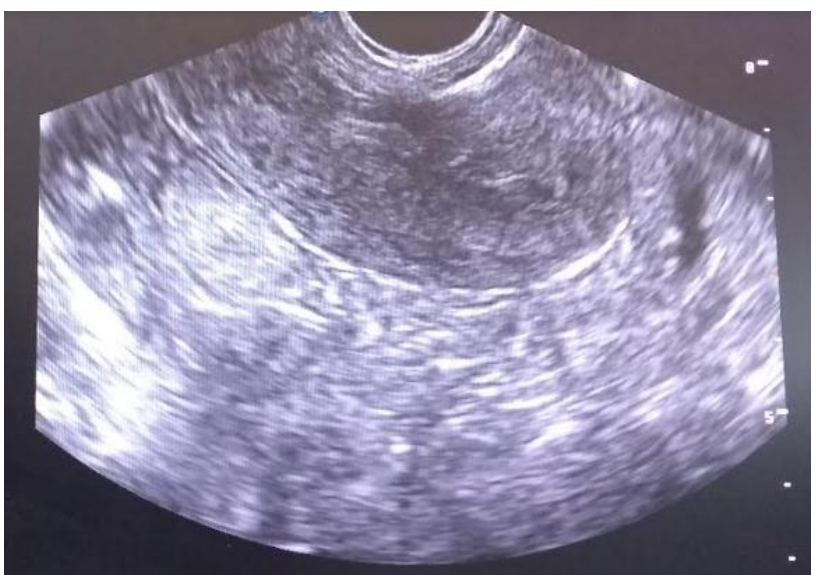

Fig. 5: Ultrasound showing empty uterus on day 39

\section{Management}

The counseling about various treatment modalities was given to the patient and her attenders and they preferred for medical management. The first dose when beta hCG was $1634 \mathrm{mIU} / \mathrm{ml}$ day 0 of injection methotrexate was given intramuscularly. After 4 days beta hCG was repeated and found to be $1502 \mathrm{mIU} / \mathrm{ml}$, hence the dose was repeated. 6 days later on day 10 beta hCG level decreased to $703 \mathrm{mIU} / \mathrm{ml}$, on the same day TVS was done gestational sac with very little decrease in size was seen therefore it was planned to repeat methotrexate injection. She was observed as outpatient after discharge till beta hCG reached normal level on day 39 with 6 doses of methotrexate. Repeat TVS was done and no gestational sac was found. Patient was also educated about using contraception.

\section{Discussion}

In last few decades there is drastic increase in cesarean sections that has enlightened us about few complications like CSP which were infrequent in the past. It was in 1978 when the first CSP as a postabortal haemorrhage was reported by Larsen and Solomon, the authors called it as suterine scar sacculus. ${ }^{11}$ The aetiology of CSP is unclear still. CSP is separated from endometrial cavity and endocervical canal and the gestational sac is covered by the fibrous tissues and myometrium of the cesarean section scar. It is via a minute tract in the cesarean section scar tissue $e^{4,13}$ early invasion of myometrium occurs or in the poorly healed cesarean section scar the implantation of gestational sac happens. On an average CSP was diagnosed between 5 to 11.6 weeks of gestational age. CSP occurs 6 to 12 months after prvious cesarean section. Development of CSP has many indirectly related risk factors - the number of previous cesarean sections, its indications, the time period between the previous cesarean and the present pregnancy.

The CSP may end as a abortion if vascular connections are lost while growing, or it may continue to grow gaining new stronger vascular connections leading into a low-lying adherent placenta with or without invasion of nearby organs . Mostly CSP do not cross beyond the first trimester. If progressed to the second or third trimester severe 
complications occurs. Early diagnosis is more important to avoid serious complications.

It's mostly an accidental USG finding, Patients are mostly asymptomatic, very few present with mild painless vaginal bleeding, mild to moderate abdominal pain and it becomes severe if CSP ruptures A patient with a ruptured CSP may collapse at any time. If the condition is not diagnosed on time, a simple dilatation and curettage may result in massive hemorrhage and unexpected complications. $\mathrm{s}$

TVS $^{15}$ with color Doppler ${ }^{2}$ is a diagnostic tool. MRI is also help full.

The ultrasound features for diagnosis are as follows

1. Cervical canal and uterus would be empty

2. Discontinuity on the anterior wall of the uterus;

3. The myometrium between the bladder and the sac is either diminished or empty; ${ }^{15}$

4. Low impedance high velocity peri-trophoblastic vascular flow visibly surrounding the sac is visible in Doppler examination.

The line of management of CSP is not there as it's a very rare condition. Our main aim of treatment should be prevention of huge blood loss and to preserve the uterus to maintain future fertility. Before deciding the method of treatment one has to consider the gestational age, hCG levels, and presence/absence of cardiac activity. Both medical and surgical management are available. The surgical management has conservative and radical methods. The radical procedure is hysterectomy when the uterus is ruptured or if bleeding is uncontrollable. The conservative procedure includes (i) evacuation of the pregnancy and repair of the uterine defect by laparotomy or laparoscopy, (ii) dilatation and curettage and excision of trophoblastic tissues using laparotomy or laparoscopy ${ }^{6,7}$ and (iii) bilateral hypogastric ligation. ${ }^{9}$ The medical treatment is MTX administration locally or systemically. ${ }^{8}$ Newer addition is the uterine artery embolisation UAE. ${ }^{3,10}$ Though UAE is helpful in treating stable cases it cannot be used as a primary line therapy.

Asymptomatic patients, hemodynamically stable woman with enraptured CSP less than eight weeks gestation and a USG finding of less than $2 \mathrm{~mm}$ myometrial thickness between the CSP and the bladder can be treated conservatively. The first line of treatment for CSP is administration of MTX. It can be used as localy, systemically or combined. Use of MTX systemically require repeated doses due to its short half-life ie 10 hours. For hCG levels less than $5000 \mathrm{IU} / \mathrm{L}^{18} \mathrm{MTX}$ is effective if given systemically. But intralesional or other methods has to be considered if hCG levels are greater than 5000 IU/L. Uterine rupture has to be ruled out before starting medical management. The patient should be prepared to undergo surgery if medical treatment fails or the CSP ruptures. The medical treatment is of high cost and regular follow up is mandatory.
There are successful viable intrauterine pregnancy reported following a conservative management of CSP .The location of the new gestational sac is confirmed early by TVS and the woman should be closely observed during the entire pregnancy as the risk of placenta accreta is more. She can be allowed for spontaneous vaginal delivery unless there is obstetric indication for an operative delivery, pregnancy should be terminated by cesarean section if there is a history of ruptured CSP in past or a very thin or absent myometrium between the CSP and bladder is present to prevent the risk of a spontaneous uterine rupture.

In our case, the patient did not want to have a surgical procedure and also she was very stable, so medical treatment was given.

\section{Follow-up}

Beta hCG levels are periodically monitored for follow-up of the patients after medical management. Once hCG level becomes $25 \mathrm{IU} / \mathrm{L}$, and ultrasound is to be done to confirm that there is no retained products of conception. Patients are advised to avoid future pregnancy for next one to two years at least minimum of 3 months and also to use any method of contraception.

\section{Conclusion}

This article proves that CSP, a life threatening condition with deadly complications can be treated successfully by systemic methotrexate injection. Complete assessment of the previous scar by ultrasound should be made a routine in all pregnant woman with previous history of a cesarean section to prevent CSP. Thus Cesarean scar pregnancy can be effectively managed by systemic administration of methotrexate at the cost of prolonged follow up.

\section{Consent}

Informed consent from the patient for publication of this paper and images is obtained.

\section{Conflict of Interest: None.}

\section{References}

1. Tulpin L, Morel O, Malartic C, Barranger E. Conservative management of a Cesarean scar ectopic pregnancy: a case report. Cases J 2009;2(8):7794.

2. Rotas MA, Haberman S, Levgur M. Cesarean scar ectopic pregnancies: etiology, diagnosis, and management. Obstet Gynecol 2006;107:1373-81.

3. Sugawara J, Senoo M, Chisaka H, Yaegashi N, Okamura K. Successful conservative treatment of a cesarean scar pregnancy with uterine artery embolization. Tohoku J Exp Med 2005;206:261-265. doi: 10.1620/tjem.206.61.

4. Vial Y, Petignat P, Hohlfeld P. Pregnancy in a cesarean scar. Ultrasound Obstet Gynecol 2000;16:592-3. doi: 10.1046/j.1469-0705.2000.00300-2.x.

5. Seow KM, Hwang JL, Tsai YL. Ultrasound diagnosis of a pregnancy in a Cesarean section scar. Ultrasound Obstet Gynecol 2001;18:547-549. doi: 10.1046/j.09607692.2001.00569.x.

6. Seow KM, Cheng WC, Chuang J, Lee C, Tsai YL, Hwang JL et al. Methotrexate for cesarean scar pregnancy after in vitro 
fertilization and embryo transfer. A case report. $J$ Reprod Med 2000;45:754-57.

7. Godin PA, Bassil S, Donnez J. An ectopic pregnancy developing in a previous caesarian section scar. Fertil Steril 1997;67:398-400. doi: 10.1016/S0015-0282(97)81930-9.

8. Persadie RJ, Fortier A, Stopps RG. Ectopic pregnancy in a caesarean scar: a case report. J Obstet Gynaecol Can 2005;27:1102-06.

9. Kung FT, Huang TL, Chen CW, Cheng YF. Image in reproductive medicine. Cesarean scar ectopic pregnancy. Fertil Steril 2006;85:1508-1509. doi: 10.1016/j.fertnstert.2005.12.016.

10. Yang MJ, Jeng MH. Combination of transarterial embolization of uterine arteries and conservative surgical treatment for pregnancy in a cesarean section scar. A report of 3 cases. $J$ Reprod Med 2003;48:213-6.

11. Larsen JV, Solomon MH. Pregnancy in a uterine scar sacculus-an unusual cause of postabortal haemorrhage. A case report. S Afr Med J 1978;53(4):142-3.

12. Muraji M, Mabuchi S, Hisamoto K, Muranishi M, Kanagawa T, Nishio Y, et al. Cesarean scar pregnancies successfully treated with methotrexate. Acta Obstet Gynecol Scand 2009;88(6):720-23.

13. 13.Jurkovic D, Hillaby K, Woelfer B, Lawrence A, Salim R, Elson CJ et al. First-trimester diagnosis and management of pregnancies implanted into the lower uterine segment Cesarean section scar. Ultrasound Obstet Gynecol 2003;21(3):220-27.

14. Seow KM, Huang LW, Lin YH, Lin MY, Tsai YL, Hwang JL et al. Cesarean scar pregnancy: issues in management. Ultrasound Obstet Gynecol 2004;23(3):247-53.

15. Jurkovic D, Hillaby K, Woelfer B, Lawrence A, Salim R, Elson CJ et al. First-trimester diagnosis and management of pregnancies implanted into the lower uterine segment Cesarean section scar. Ultrasound Obstet Gynecol 2003;21(3):220-27.

16. Maymon R, Halperin R, Mendlovic S, Schneider D, Vaknin Z, Herman A, et al. Ectopic pregnancies in Caesarean section scars: the 8 year experience of one medical centre. Hum Reprod 2004;19(2):278-84.

17. Al Hashmi S, Maiti S, Macfoy D. Successful conservative management of ectopic pregnancy in Caesarean section scar. BMJ Case report 2012; 2012: bcr-2012-006925.

18. Ash A, Smith A, Maxwell D. Caesarean scar pregnancy. BJOG 2007;114(3):253-63.

How to cite this article: Krishnamoorthy G, Aiyswarya, A success of cesarean scar ectopic pregnancy by conservative treatment. Indian J Obstet Gynecol Res 2019;6(2):216-219. 